\title{
Prune belly syndrome in an Egyptian infant with Down syndrome: $A$
} case report

\author{
Kotb A Metwalley ${ }^{1}$, Hekma S Farghalley² and Alaa A Abd-Elsayed*3
}

\author{
Address: ${ }^{1}$ Department of Paediatrics, Faculty of Medicine, Assiut University, Assiut, Egypt, ${ }^{2}$ Department of Paediatrics, Al-Mabarah Hospital, \\ Assiut, Egypt and ${ }^{3}$ Department of Public Health and Community Medicine, Faculty of Medicine, Assiut University, Assiut, Egypt \\ Email: Kotb A Metwalley - kotb72@hotmail.com; Hekma S Farghalley - hekma73@hotmail.com; Alaa A Abd- \\ Elsayed* - alaaawny@hotmail.com \\ * Corresponding author
}

Journal of Medical Case Reports 2008, 2:322 doi:10.1186/1752-1947-2-322

This article is available from: http://www.jmedicalcasereports.com/content/2/1/322

(C) 2008 Metwalley et al; licensee BioMed Central Ltd.

This is an Open Access article distributed under the terms of the Creative Commons Attribution License (http://creativecommons.org/licenses/by/2.0), which permits unrestricted use, distribution, and reproduction in any medium, provided the original work is properly cited.

\begin{abstract}
Introduction: Prune belly syndrome is a rare congenital anomaly of uncertain aetiology almost exclusive to males. The association between prune belly syndrome and Down syndrome is very rare.

Case presentation: A 4-month-old Egyptian boy was admitted to our institute for management of acute bronchiolitis. He was born at full term by normal vaginal delivery. His mother, a 42-yearEgyptian villager with six other children, had no antenatal or prenatal care. On examination, the boy was found to be hypotonic. In addition to features of Down syndrome, karyotyping confirmed the diagnosis of trisomy 2I. Ultrasound examination of the abdomen showed bilateral gross hydronephrosis with megaureter. Micturating cystourethrography showed grade $V$ vesicoureteric reflux bilaterally with no urethral obstruction. Serum creatinine concentration was $90 \mu \mathrm{mol} /$ litre, serum sodium was $132 \mathrm{mmol} /$ litre and serum potassium was $5.9 \mathrm{mmol} / \mathrm{litre}$.

Conclusion: We report an Egyptian infant with Down syndrome and prune belly syndrome. The incidence of this association is unknown. Routine antenatal ultrasonography will help in discovering renal anomalies which can be followed postnatally. Postnatal detection of prune belly syndrome necessitates full radiological investigation to detect any renal anomalies. Early diagnosis of this syndrome and determining its optimal treatment are very important in helping to avoid its fatal course.
\end{abstract}

\section{Introduction}

Prune belly syndrome (PBS) (bilateral gross hydronephrosis, megaureter, and megacystis with abdominal muscle deficiency) is a rare congenital anomaly of uncertain aetiology almost exclusive to males $[1,2]$. It is caused by urethral obstruction early in development resulting in massive bladder distension and urinary ascites, leading to degeneration of the abdominal wall musculature and failure of testicular descent. The impaired elimination of urine from the bladder leads to oligohydramnios, pulmonary hypoplasia, and Potter's facies. The syndrome has a broad spectrum of affected anatomy with different levels of severity. The exact aetiology of PBS is unknown, although several embryologic theories attempt to explain the anomaly [3]. The association between PBS and Down syndrome (DS) was reported in a few cases. The cause of this association is still unknown. We report a 4-monthold Egyptian boy with PBS and features of DS. Diagnosis 
was confirmed by karyotyping and micturating cystourethrography.

\section{Case presentation}

A 4-month-old Egyptian boy was admitted to our pediatric emergency department for management of acute bronchiolitis. He was born at home after full term normal vaginal delivery with no previous hospitalization. His mother, a 42-year-old Egyptian villager with six other children, had no antenatal or prenatal care. On examination, he was found to be hypotonic. In addition to features of DS, karyotyping confirmed the diagnosis of trisomy 21. Abdominal examination revealed a distended abdomen with thin wrinkled skin and visible peristalsis (Figure 1) and with palpable kidneys and bilateral undescended testes. His blood pressure was within the normal range and cardiac examination was normal both by clinical examination and echocardiography. Ultrasound examination of the abdomen showed bilateral gross hydronephrosis with megaureter. Micturating cystourethrography showed grade $\mathrm{V}$ vesicoureteric reflux bilaterally with no urethral obstruction. Serum creatinine concentration was 90 $\mu \mathrm{mol} / \mathrm{l}$, serum sodium was $132 \mathrm{mmol} /$ litre and serum potassium was $5.9 \mathrm{mmol} / \mathrm{l}$. The patient died from respiratory failure 5 days after hospital admission.

\section{Discussion}

Renal hypoplasia, hydroureter hydronephrosis, ureterovesical and ureteropelvic junction obstruction, posterior urethral valve and vesicoureteric reflux, have all been associated with DS [4]. PBS has rarely been reported in association with DS $[5,6]$. Al Harbi reported a similar case of PBS and DS in a girl [7]. Current theories on the pathogenesis of PBS suggest some yet unknown mesodermal

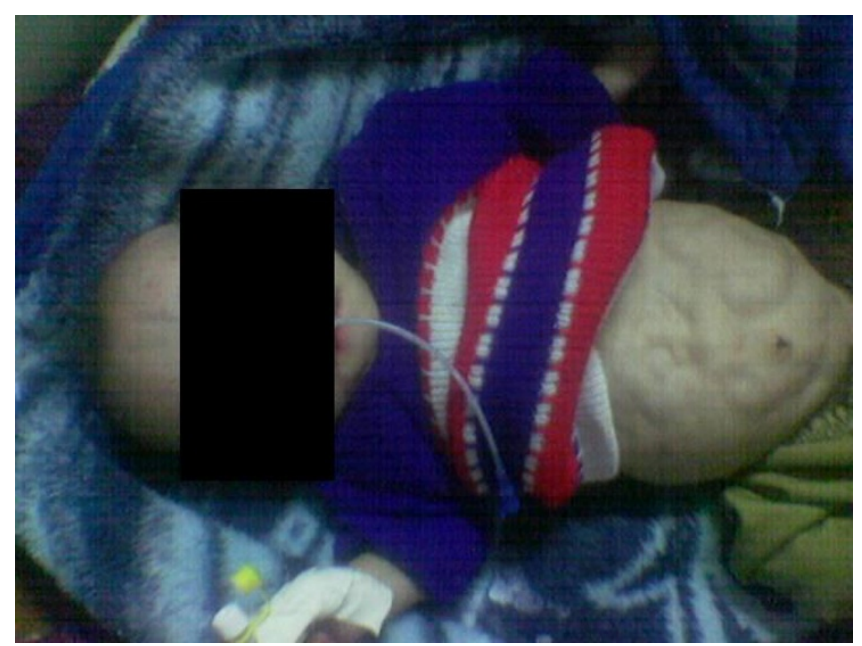

Figure I

Prune belly syndrome in a child with Down syndrome. injury and or in utero urinary tract obstruction [8]. A genetic cause may also be possible. However, this does not exclude modification of the severity of PBS by the associated chromosomal anomaly [9]. It has been recognized recently that many genes involved in renal nephrogenesis either reappear or are expressed to a markedly greater degree in renal disease [10]. The prognosis of PBS is poor with stillbirths and early infant deaths being common [11]. Diao et al. reported that renal failure is the main cause of death in PBS [2]. The lack of prenatal care prevented the analysis of the family pedigree and possible prenatal diagnoses of both syndromes.

\section{Conclusion}

We report an Egyptian infant with DS and PBS. The incidence of this association is unknown, however, there appears to be an incidence of renal and urological anomalies in patients with DS that is higher than previously reported. Routine antenatal ultrasonography will help in discovering renal anomalies which can be followed postnatally. Postnatal detection of PBS necessitates full radiological investigations to detect any renal anomalies. Early diagnosis of this syndrome and determining its optimal treatment are very important in helping to avoid its fatal course.

\section{Abbreviations}

DS: Down syndrome; PBS: Prune belly syndrome.

\section{Competing interests}

The authors declare that they have no competing interests.

\section{Authors' contributions}

KM and AAA-E participated in the clinical management of the case and in manuscript writing. HF participated in the clinical management of the case.

\section{Consent}

Written informed consent was received from the patient's next-of-kin for publication of this case report and any accompanying images. A copy of the written consent is available for review by the Editor-in-Chief of this journal.

\section{References}

I. Williams DI, Burkholder GV: The prune belly syndrome. J Urol 1967, 98:244-25।.

2. Diao B, Diallo Y, Fall PA, Ngom G, Fall B, Ndoye AK, Fall I, Ba M, Ndoye M, Diagne BA: Prune Belly syndrome: Epidemiologic, clinic and therapeutic aspects. Prog Urol 2008, $18(7): 470-474$.

3. Woods AG, Brandon DH: Prune belly syndrome. A focused physical assessment. Adv Neonatal Care 2007, 7(3): |32-|43.

4. Egli F, Stalder G: Malformations of kidney and urinary tract in common chromosomal aberrations. I. Clinical studies. Humangenetik 1973, I 8: I-I5.

5. Amacker EA, Grass FS, Hickey DE, Hisley JC: Brief clinical report: an association of prone belly anomaly with trisomy $21 . \mathrm{Am} J$ Med Genet 1986, 23:919-923.

6. Zerres K, Volpel MC, Weib H: Cystic kidneys: genetics, pathologic anatomy, clinical picture and prenatal diagnosis. Hum Genet 1984, 68:104-135. 
7. Al Harbi NN: Prune-belly anomalies in a girl with Down syndrome. Pediatr Nephrol 2003, I 8:1 I91-II 92.

8. Vogt BA, Davis ID, Avner ED: Eagle-Barrett syndrome. In Care of the High-risk Neonate 5th edition. Edited by: Klaus MH, Fanaroff AA. Philadelphia, PA: WB Saunders; 2001:443.

9. Adeyokunnu AA, Familusi JB: Prune belly syndrome in two siblings and a first cousin. Possible genetic implications. Am J Dis Child 1982, 136:23-25.

10. Dolan V, Hensey C, Brady HR: Diabetic nephropathy: renal development gone awry? Pediatr Nephrol 2003, I 8:75-84

11. National Organization for Rare Disorders: Prune belly syndrome. [http://www.rarediseases.org/search/rdbd].

Publish with Bio Med Central and every scientist can read your work free of charge

"BioMed Central will be the most significant development for disseminating the results of biomedical research in our lifetime."

Sir Paul Nurse, Cancer Research UK

Your research papers will be:

- available free of charge to the entire biomedical community

- peer reviewed and published immediately upon acceptance

- cited in PubMed and archived on PubMed Central

- yours - you keep the copyright

Submit your manuscript here:

http://www.biomedcentral.com/info/publishing_adv.asp 